\title{
Evaluation of human-induced surgical injuries to animals: a retrospective study
}

\author{
BAŞAK KURT, METE CIHAN \\ Department of Surgery, Faculty of Veterinary Medicine, Kafkas University, Kars, Turkey
}

Kurt B., Cihan M.

\section{Evaluation of human-induced surgical injuries to animals: a retrospective study}

Summary

This retrospective study evaluated surgical cases occurring in animals due to human errors that were admitted to the Department of Surgery, Faculty of Veterinary Medicine, Kafkas University over six years (2012-2018). A total of 4239 animals were examined and diagnosed with surgical problems caused by humans according to our clinical records. Among these, 462 (294 large ruminants, 147 carnivores, 18 horses and 3 small ruminants) were included in the study. The animals were subjected to harm during interventions for dystocia $(n=189)$, road traffic accidents $(n=143)$, injection failures $(n=73)$, gunshot injuries $(n=24)$, cutting and penetrating injuries $(n=22)$ and other problems $(n=11)$. Recovery was recorded in 420 of treated cases, 18 were euthanized, 14 died, 7 underwent amputation and 3 were slaughtered. Human-induced surgical injuries are worth noting in these cases. Although the majority of the animals were treated, issues such as treatment expenses, weight loss in farm animals during the treatment period and property damages due to road traffic accidents cause serious economic losses. Therefore, owners should be made aware of human errors that generate vital and economic costs. Practices without adequate knowledge or experience should be prevented in the field and veterinarians should supervise their personnel and owners regarding postoperative care and other treatment procedures.

Keywords: birth injuries, errors, gunshot wounds, injections, traffic accidents

Humans may intentionally or unintentionally harm animals in various ways. Injuries may occur as a result of intentional or unintentional medical practices performed for treatment purposes, as well as due to wilful damage or traffic accidents. Violent behaviour towards animals is encountered in many parts of the world and there are many organizations fighting this problem. The leading examples of sadism towards animals are physical abuse, including striking animals with various objects, kicking, shooting with firearms and burning, as well as exclusionary behaviour, including deprivation of food, water, shelter or healthcare $(9,11)$. These behaviours are the cause of several surgical problems, including impact-induced trauma, wounds caused by sharp/penetrating objects and lesions resulting from chemical substances $(10,18)$.

Trauma caused by traffic accidents is occurring more frequently due to shrinking animal habitats (11). Many studies suggest that these traumas are frequent, but appear to have a lower incidence, because the animal victims are treated at private veterinary clinics rather than at state animal hospitals (14). Various types of surgical injuries, ranging from scratches to wounds with tissue loss to extremity fractures as well as multiple traumas are observed because of traffic accidents, particularly in stray and wild animals (16). Furthermore, in traffic accidents not just animals, but people can be injured and vehicles damaged, resulting in health and repair expenses, as well as losses to the economy.

Irresponsible practices performed for treatment purposes can cause more harm than good to animal patients. Inappropriate manipulations and excessive manual or mechanical force applied by animal owners or veterinarians during difficult births cause orthopaedic problems and traumatic injury to nerves and soft tissues $(1,17)$. Peripheral nerve lesions are also frequently encountered due to botched injections by veterinarians (7). Depending on the resultant nerve damage and pretreatment period, the prognosis is often poor, even if the medical treatment is successful (15). Another misapplication is bandage treatment without having sufficient knowledge regarding the underlying condition. Complications such as open and infected fractures and gangrene as well as delayed fracture treatment are encountered in many patients because of irresponsible bandage practices for extremity fractures performed by animal owners $(3,19)$. 
Curable disorders and non-curable disorders, including disability or even death, can occur in animals because of all these causes. Furthermore, these incidents cause substantial economic losses.

This study aimed to evaluate surgical problems caused by human errors diagnosed based on clinical examinations and medical histories according to our clinical records in animals.

\section{Material and methods}

The study material consisted of 462 animal patients diagnosed with diseases resulting from human error between 01.01.2012 and 01.01.2018 in the Surgical Clinic of the Veterinary Faculty at Kafkas University. We evaluated the patient information which was caused by human errors according to clinical examinations and medical histories (received from the owners or persons who brought stray animals to the clinic) obtained from the clinical records.

The incidence and the distribution of the cases by species were examined. In this context, during the specified period, the number of all animal brought to the clinic and the number of patients with human-induced surgical problems were recorded and the percentage of numerical data was calculated.

\section{Results and discussion}

A total of 4239 patients were brought to our clinics during a six years period, and $462(10.89 \%)$ had human-induced surgical problems. Distribution of the cases according to species were presented in Figure 1. The human errors and the number and percentage of these cases were presented in Table 1 . Recovery was recorded in 420 of treated cases; 18 were euthanized, 14 died, 7 underwent amputation and 3 were slaughtered.

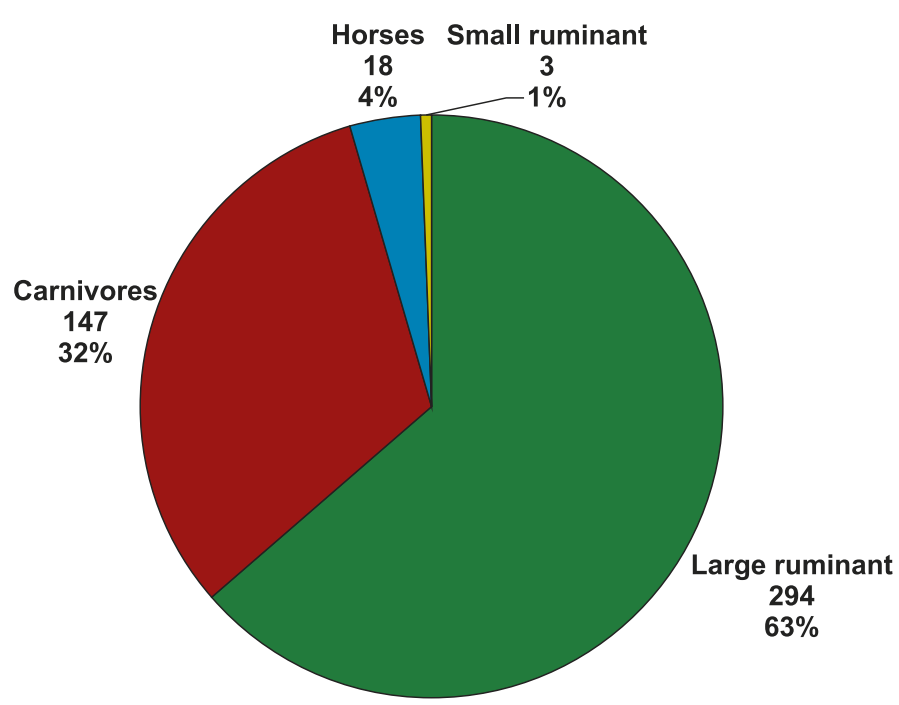

Fig. 1. Distribution of the human-induced surgical cases according the species

unilateral and bilateral fractures were encountered. In some animals, there were gangrene cases with fractures that occurred due to the delay of treatment or incorrect bandaging by animal owners.

It was determined in the cases of fractures evaluated according to clinical history that these calves were exposed to excessive force and harmful materials, and that motorized vehicles were used during birth. All cases of dislocations occurred by incorrect-tractioninduced were coxofemoral luxations.

The animals involved in traffic accidents included 113 dogs, 23 cats, 4 cows, 1 calf, 1 lamb and 1 horse. The disorders determined due to traffic accidents were presented in Table 2. Fractures occurred in several bones in some cases and in only one bone in other cases.

All interventional errors during dystocia were diagnosed in calves. Of these, 157 were Simmental, 23 were Brown Swiss, 5 were Zavot and 4 were Native Black. A total of 141 were male and 48 were female. The disorders determined due to interventional errors were presented in Table 2. Soft tissue traumas were diagnosed as open wounds, contusions, tendon injuries and tarsal instability. Fractures were found in all extremities and mandibles. Both

Tab. 1. Numbers and percentages of human-induced surgical injuries

\begin{tabular}{|l|c|c|}
\hline \multicolumn{1}{|c|}{ Human errors } & $\begin{array}{c}\text { Number of cases } \\
\text { (n) }\end{array}$ & $\begin{array}{c}\text { Percentage of cases } \\
\text { (\%) }\end{array}$ \\
\hline Errors made in birth intervention & 189 & 40.90 \\
\hline Traffic accidents & 143 & 30.95 \\
\hline Injection failures & 73 & 15.80 \\
\hline Gunshot injuries & 24 & 5.19 \\
\hline Wounding with sharp/penetrating objects & 22 & 4.76 \\
\hline $\begin{array}{l}\text { Other (kicking with rigid bodies - 5, postoperative } \\
\text { complications - 5, incorrect probe application - 1) }\end{array}$ & 11 & 2.38 \\
\hline
\end{tabular}

Tab. 2. Number and diversity of surgical cases determined due to human errors

\begin{tabular}{|c|c|c|c|c|c|c|c|c|}
\hline $\begin{array}{l}\text { Surgical cases/ } \\
\text { Human errors }\end{array}$ & $\begin{array}{l}\text { Soft tissue } \\
\text { trauma }\end{array}$ & Fracture & Luxation & $\begin{array}{c}\text { Sciatic } \\
\text { paralysis }\end{array}$ & Abscess & $\begin{array}{l}\text { Spastic } \\
\text { paresis }\end{array}$ & $\begin{array}{l}\text { Rumen fistula } \\
+ \text { Peritonitis }\end{array}$ & $\begin{array}{l}\text { Esophageal } \\
\text { rupture }\end{array}$ \\
\hline $\begin{array}{l}\text { Errors made in birth } \\
\text { intervention }\end{array}$ & 63 & 118 & 8 & - & - & - & - & - \\
\hline Traffic accidents & 56 & 85 & 2 & - & - & - & - & - \\
\hline Injection failures & - & - & - & 48 & 24 & 1 & - & - \\
\hline Gunshot injuries & 24 & - & - & - & - & - & - & - \\
\hline $\begin{array}{l}\text { Wounding with sharp/ } \\
\text { penetrating objects }\end{array}$ & 14 & - & - & - & - & - & 8 & - \\
\hline Others & 5 & - & - & - & 5 & - & - & 1 \\
\hline
\end{tabular}




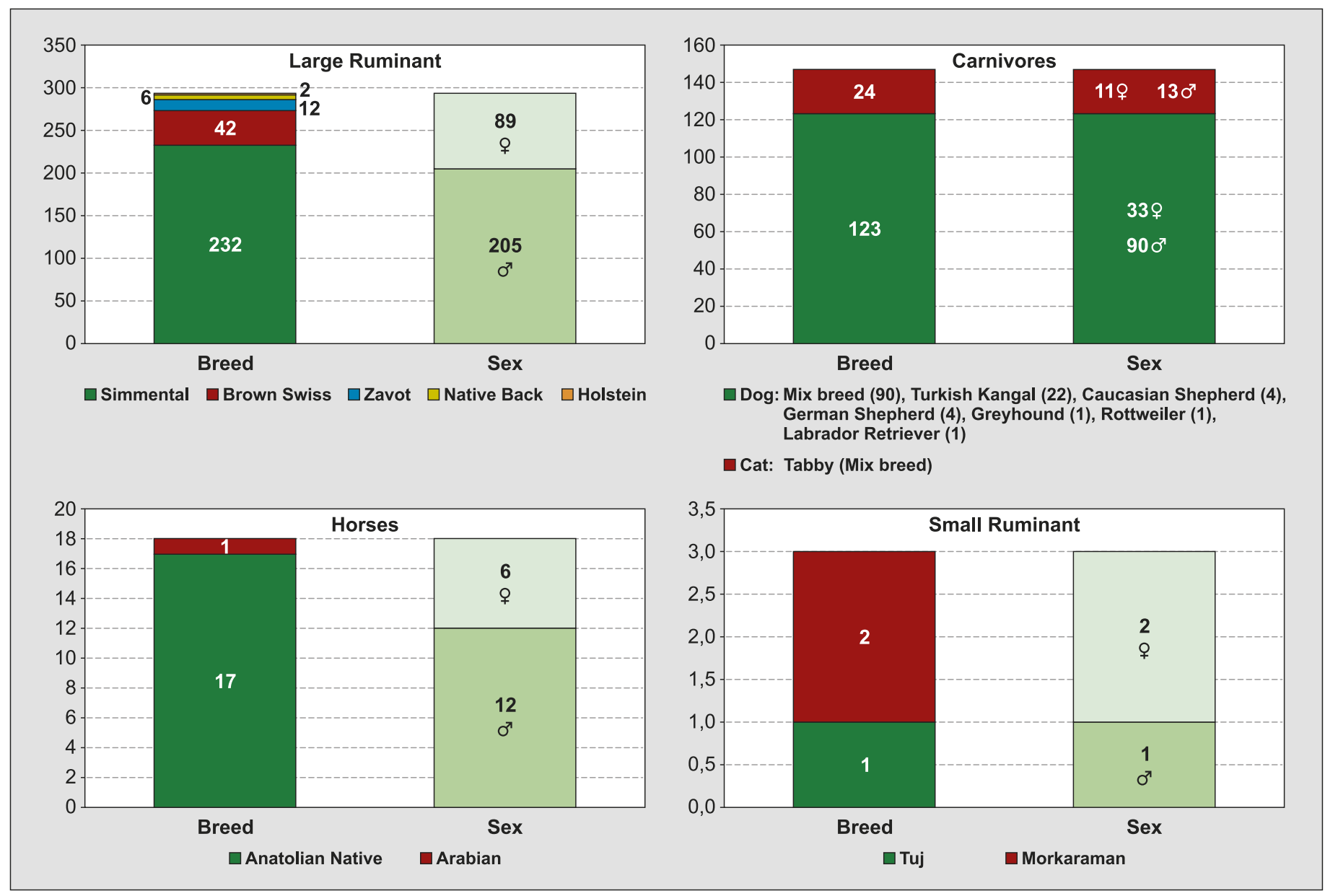

Fig. 2. Number of the cases according to species, breeds and sex

Problems due to injection errors occurred in 48 patients. The disorders determined due to injection failures were presented in Table 2. Of these patients, 71 were large ruminants, 1 was a dog and 1 was a lamb.

Gunshot injuries were found in 16 horses, 6 dogs and 2 cows. Records of clinical history and $x$-ray findings revealed that 22 of these animals were injured by shotgun shells and 2 were injured by single bullets.

Among the cases wounded by sharp/penetrating objects, 8 had ruminal tympany and it was determined that they were wounded due to erroneous animal owner intervention, whereas other animals were found to be wounded intentionally. The disorders determined due to sharp/penetrating objects were presented in Table 2 .

Other traumas were as follows: being struck by rigid objects (5), postoperative complications (5) and incorrect probe application (1). The cases that were struck by rigid objects were determined to have been wounded intentionally. The cases with complications in the surgical area were determined to have been deprived of necessary care in the post-operative period. It was observed in cases with incorrect probe application that insufficiently informed methods were applied, and these patients were brought to our clinic after the methods were not successful.

The number of the cases according to species, breeds and sex were presented in Figure 2.
The number and percentage of the cases according to the intentional or unintentional cause were presented in Figure 3.

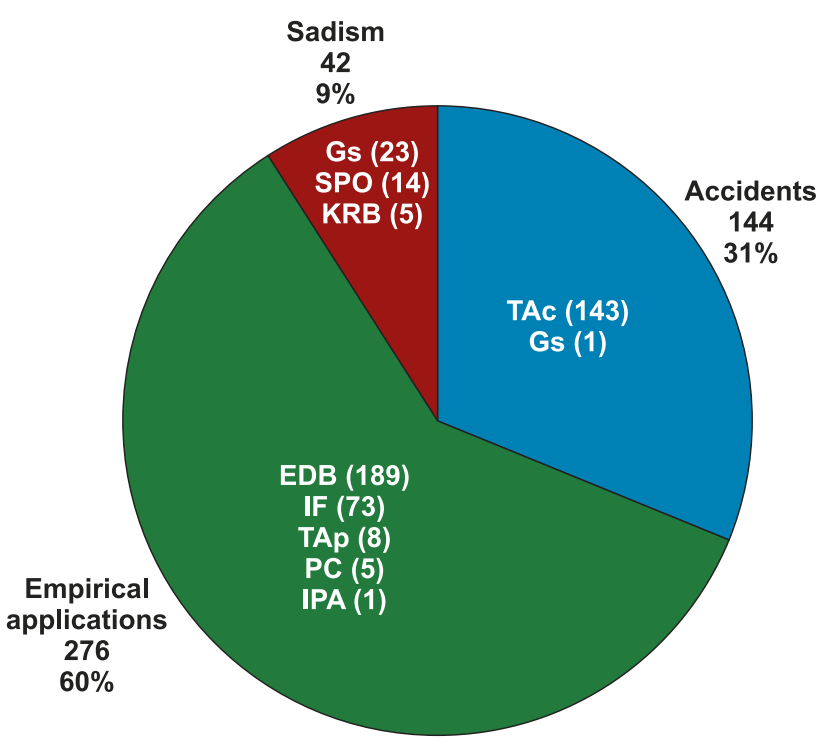

Fig. 3. Number and percentage of the cases according to the cause

Explanations: Gs - gunshots; SPO - sharp/penetrating objects; KRB - kicking with rigid bodies; TAc - traffic accidents; EDB - errors during birth intervention; IF - injection failures; TAp - trocar applications; PC - postoperative complications; IPA incorrect probe application 
We examined 4239 patient records who were brought to our clinics over a period of six years. Human-induced surgical problems were identified in 462 of these patients.

The most common problems caused by human were mistakes made in intervention during dystocia $(40.90 \%)$. And the most common problems of these were fractures. It is known that ropes and chains used for traction during difficult births cause open or closed fractures as well as soft-tissue traumas (20). Aksoy et al. (1) observed fractures of the corpus mandibula, metacarpus, radius-ulna, femur, metatarsus, tibia and humerus, and these fractures occurred during difficult births. Similarly, human-induced fractures in the mandibula and extremities were found in this study. These kinds of injuries are important because the length of hospitalization is prolonged and treatment costs reach high figures due to orthopaedic injuries. Incorrect traction practices during birth interventions continue to present a serious problem despite the availability of many private veterinary clinics in the area. The numbers of fracture cases were remarkable in culture breeds and male animals. This may be because calves of culture breeds are larger than those of other breeds, and male calves are larger than female calves. We observed that excessive force was applied to calves during traction in cases with fractures. Additionally, incorrect application of traction technique and birth intervention by persons with inadequate knowledge in this regard were the main reasons for these traumas.

In this study, the second most common humaninduced surgical problems were caused by traffic accidents (30.95\%). Rochlitz et al. (14) reported that traffic accidents were among the most common causes of injury and death in cats, emphasizing their effects on animals as well as the resulting emotional trauma for animal owners as an important problem. Traffic accidents are also reported to be the most common cause of major trauma in dogs (2). In the present study, most of the patients involved in traffic accidents were dogs. The number of fractures was higher in surgical problems due to traffic accidents than in other problems. Bell (2) also referred to traffic accidents and falls as the two most important causes of fractures. In this study, it is noteworthy that the patients who suffered from traffic accidents were largely stray dogs. Yiğit et al. (21) reported that stray animals are significantly prone to traffic accidents and these accidents resulted in loss of life and property because of the lack of current deterrent penalties (Animal Protection Law/5199-21). The number of stray animals increases daily due to uncontrolled breeding, and the risk of involvement in traffic accidents of these animals increases due to rapid urbanization. These patients brought to our clinic by animal lovers are also important in terms of obtaining information about overpopulation of dogs in the area.
In this study, the third most common human-induced surgical problem was incorrect injections (15.80\%). Sciatic nerve paralysis occurring in most of these patients clearly demonstrates the gravity of the irreversible damage to these animals while trying to treat them. Durmuş et al. (5) reported that prognosis was poor in $N$. ischiadicus paralysis, and it was not possible to obtain a positive outcome in medical treatment in such cases; therefore, muscle transposition could be successfully applied in dogs for this purpose. Similarly, Kilıç et al. (7) encountered peroneal paralysis in 36 sheep after herd vaccination due to incorrect injections or side effects of the medications at the injection site and they performed muscle transposition when these patients did not respond to medical treatment.

In our study, we found that injections in large ruminants were mostly carried out by animal owners. The results showed that the severity of problems increases and various complications arise because of erroneous treatment practices performed by animal owners using their own means and knowledge instead of that of veterinarians. We believe that animal owners try to make therapeutic applications because of many reasons which are the main problems of this region, although it is not legal to perform medical intervention to animals by the owners in our country (Animal Protection Law/5199-7). These problems may be harsh climatic conditions or veterinary clinics located away from the livestock areas or lack of transport facilities or economic inefficiencies.

In the present study, the fourth most common humaninduced surgical problem was gunshot injury (5.19\%). Gunshot injuries in the field of veterinary medicine vary based on the animals' living areas. Gunshot injuries were reported to be more common in large cities and rural areas. They occur in animals accidentally, as a result of defensive actions or as a result of intentional actions (13). Gunshot wounds were reported to be rare in horses (12). However, it was noteworthy in our study that horses had more gunshot wounds than did other species. This situation can be associated with having many of free horses called jade in the region. These horses are used for their strength in summer season and are released to feed in the winter season to grassland by the owners. In the period when the horses are free, the possibility of exposure to a traumatic event with them increases. According to clinical records, in only one case in our study the owner acknowledged that the gunshot injury was his own fault. Although no clear information was obtained in other cases, we concluded on the basis of conflicting statements that the injuries were inflicted intentionally. Considering the damage and high mortality in animals due to both traffic accidents and gunshot injuries, as well as the possibility of people being traumatized in these cases, even more human-induced losses are encountered. 
In this study, the least common human-induced surgical problems were found to be injuries caused by sharp and penetrating objects $(4.76 \%)$ and other traumas $(2.38 \%)$. The most common cause of the injuries caused by sharp and penetrating objects were irresponsible interventions on the part of animal owners in tympany cases. In cases of life-threatening tympany, it is necessary to remove the gas accumulated in the rumen using a trocar on an emergent basis (4). However, this procedure may result in complications such as emphysema, wound infections and peritonitis (6). Indeed, in our study, all such patients had ruminal fistulas and peritonitis. The fact that the cases in our study where intentionally induced injuries with sharp/ penetrating objects were seen at a higher rate than were treatment applications reveals the extent of malicious human behaviour towards animals.

Although they were encountered at a very low rate in our study, incorrect probe applications and post-operative complications were among the humaninduced surgical problems. These cases draw attention to the fact that unprofessional examination of patients or faulty interventions by physicians during treatment should not be ignored. It is difficult to estimate how many of our cases occurred intentionally. Nevertheless, when examining the data obtained from clinical records it was observed that the majority of the cases were empirical applications. Veterinarians must ensure that they and the staff working with them are extremely attentive during implementation. If post-operative care is performed in a clinical setting, the staff responsible for inpatient care should be informed in detail regarding the relevant post-operative care procedures. Similarly, if post-operative care is performed after discharge, the animal owners should be informed in detail regarding relevant post-operative care procedures.

This study revealed that the prevalence of humaninduced surgical problems is remarkable in magnitude. Unfortunately, there are many cases where it is not possible to prove sadism. Only the information from animal owners or animal lovers who brought patients to our clinic was taken into consideration in the present study. Although many similar cases were brought to our clinic, they could not be included because their clinical histories could not be properly obtained.

Consequently, when all these human errors are examined, we observed that the victimized animals suffer from curable disorders, but they may also encounter surgical problems causing incapacity or death. For this purpose, animal owners should be informed that human faults have both vital and economic significance in the field of veterinary medicine. They should also be informed in detail regarding out-of-clinic interventions. Municipalities should provide communication between animal shelter managers and veterinarians to maintain the stray animal population under control.
Stray animals must be kept in shelters, and animal shelters must be located in remote locations away from human habitats and highways. Sadism is still a major problem that should not be ignored. Current penal provisions of Animal Protection Law may be regulated, implemented and supervised to be a deterrent in this type of human errors. Veterinarians should fight with empirical practices in the field and should be very sensitive to comply with the rules of every practice they perform.

\section{References}

1.Aksoy Ö., Özaydın İ., Kılıç E., Öztürk S., Güngör E., Kurt B., Oral H.: Evaluation of fractures in calves due to forced extraction during dystocia: 27 cases (2003-2008). Kafkas Univ. Vet. Fak. Derg. 2009, 15, 339-344.

2. Bell C. T. P.: First aid and health care for dogs: Road traffic accident \& trauma The Lutterworth Press. Cambridge 1993, p. 80-88.

3. Calder C.: Wound management - Part 3: Bandaging complications. V.N.J. 2013, 28, 121-124.

4. Constable P. D.: Bloat in Ruminants, [in:] Aiello S. E., Moses M. A. (ed.): Wiley, Merck Veterinary Manual. Kenilworth 2016, p. 1-5.

5.Durmuş A. S., Ünsaldı E.: Fibular paralysis and its treatment in cattle. D.A.U.M. 2005, 3, 115-117.

6. Gül Y.: Ruminal tympania. Vet. Sci. 2010, 5, 73-84.

7. Kılıç E., Aksoy Ö., Özaydın İ., Öztürk S., Sözmen M., Kurt B.: Repair of peroneal paralysis by muscle transposition in sheep. Kafkas Univ. Vet. Fak. Derg. 2009, 15, 505-510.

8. Klainbart S., Bibring U., Strich D., Chai O., Bdolah-Abram T., Aroch I., Kelmer E.: Retrospective evaluation of 140 dogs involved in road traffic accidents, Vet. Rec. 2017, doi: 10.1136/vr.104293

9. McGuinness K., Allen M., Jones B. R.: Non-accidental injury in companion animals in the Republic of Ireland. Ir. Vet. J. 2005, 58, 392-396.

10. Merck M. D.: Patterns of non-accidental injury: Non-penetrating injuries, [in:] Merck M. D. (ed.): Veterinary Forensics: Animal cruelty investigation. Blackwell Publishing, Ames 2007, p. 79-100.

11. Munro H. M., Thrusfield MV.: 'Battered pets': Non-accidental physical injuries found in dogs and cats. J. Small. Anim. Pract. 2001, 42, 279-290.

12. Munsterman A. S., Hanson R. R.: Trauma and wound management: Gunshot wounds in horses. Vet. Clin. North Am. Equine Pract. 2014, 30, 453-466.

13. Pavletic M. M., Trout N. J.: Bullet, bite, and burn wounds in dogs and cats. Vet. Clin. Small Anim. 2006, 36, 873-893.

14. Rochlitz I.: Study of factors that may predispose domestic cats to road traffic accidents: Part 1. Vet. Rec. 2003, 153, 549-553.

15. Rodkey W. G.: Peripheral Nerve Surgery, [in:] Slatter D. (ed.): Saunders W. B. Company, Textbook of Small Animal Surgery. Philadelphia 1993, p. 1135 -1202 .

16. Rowden P., Steinhardt D., Sheehan M.: Road crashes involving animals in Australia. Accid. Anal. Prev. 2008, 40, 1865-1871.

17. Schuijt $G .:$ Iatrogenic fractures of ribs and vertebrae during delivery in perinatally dying calves: 235 cases (1978-1988). J. Am. Vet. Med. Assoc. 1990, 197, 1196-1202.

18. Siqueira A., Cassiano F. C., Landi M. F. A., Marlet E. F., Maiorka P. C.: Nonaccidental injuries found in necropsies of domestic cats: Review of 191 cases. J. Feline Med. Surg. 2012, 14, 723-728.

19. Smith R. K. W.: Bandages and casts. Equine Vet. Educ. 1993, 5, 108-112.

20. Steiner A.: Management of metacarpal, metatarsal, radial and tibial fractures in calves. $9^{\text {th }}$ Ann. ESVOT Congress, 16-19 April 1998, Munich-Germany, p. 95-96.

21. Yiğit A., Aslım G., Yaşar A.: Mevzuat kapsamında hayvanlar ve trafik kazaları. Karayolu Trafik Güvenliği Sempozyumu: Seçilmiş Bildiriler, Ankara-Turkey 2010, p. 376-391.

Corresponding author: Assist. Prof. Dr. Başak Kurt, Kafkas University, Faculty of Veterinary Medicine, Department of Surgery, TR36100, Kars Turkey; e-mail: basakyakin@hotmail.com 